\title{
Capital beats coal: how collecting the climate rent increases aggregate investment
}

\author{
$\underline{\text { Jan Siegmeier }}$, , Linus Mattauch $†$ Ottmar Edenhofer ${ }^{\ddagger}$ \\ October 30, 2017 \\ Suggested running title: \\ "How collecting the climate rent increases investment"
}

Acknowledgements We thank Cameron Hepburn, Matthias Kalkuhl and Anselm Schultes for insightful discussions. Financial support from the MichaelOtto-Stiftung for the Chair Economics of Climate Change at TU Berlin is gratefully acknowledged. Linus Mattauch thanks the German National Academic Foundation for financial support. His research was also supported by a postdoctoral fellowship of the German Academic Exchange Service (DAAD).

\footnotetext{
*(Corresponding author) Technical University of Berlin and Mercator Research Institute of Global Commons and Climate Change, Torgauer Str. 12-15, D-10829 Berlin, E-Mail: siegmeier@mcc-berlin.net, Phone: 0049-(0)30-3385537-222.

${ }^{\dagger}$ Institute for New Economic Thinking at the Oxford Martin School and Environmental Change Institute, School of Geography and the Environment, University of Oxford and Mercator Research Institute on Global Commons and Climate Change. E-Mail: linus.mattauch@inet.ox.ac.uk

${ }^{\ddagger}$ Technical University of Berlin, Mercator Research Institute on Global Commons and Climate Change and Potsdam Institute for Climate Impact Research. E-Mail: ottmar.edenhofer@pik-potsdam.de
} 


\title{
Capital beats coal: how collecting the climate rent increases aggregate investment
}

\author{
October 30, 2017
}

- Second revision -

\begin{abstract}
Carbon pricing is the key to decarbonizing the economy, as it regulates emission flows. However, a price on carbon also collects rents from underlying fossil resource stocks, giving rise to unexamined macroeconomic effects. This article shows that if these stocks are tradable, carbon pricing shifts aggregate investment towards alternative assets. If capital is underaccumulated, this implies lower costs of climate policy and a welfare improvement. We prove this beneficial investment shift from fossil stocks towards capital for the case of an emission trading scheme: specifically, we show that the higher the share of auctioned permits, the larger the beneficial investment effect. Further, the same holds for a 'stock instrument', under which the right to recurrently receive emission permits is a tradable asset, making the effect robust to trade restrictions on fossil stocks. Our main result contradicts the common perception of a trade-off between climate change mitigation policy and fostering growth.
\end{abstract}

JEL classification: E22, H21, H23, Q30, Q54

Keywords: carbon pricing, resource rent taxation, overlapping generations, capital underaccumulation 


\section{${ }_{24} 1$ Introduction}

Climate change mitigation is often perceived to be in conflict with economic objectives such as growth or job creation. Behind this lies a Malthusian pessimism that imposing a limit on greenhouse gas emissions to keep global warming below $2{ }^{\circ} \mathrm{C}$ will inevitably impair economic activity $!_{1}^{1}$ We show here that this need not be the case: we present a new argument that well-designed mitigation policies may enhance economic efficiency, instead of being in conflict with economic growth. Our claim is based on macroeconomic effects of rent taxation.

Enforcing a limit on cumulative emissions (a 'carbon budget') creates scarcity rents. If emissions are limited by means of carbon pricing, some of the rents will be collected by the state: for example, auctioning a fixed amount of emission permits, or implementing a carbon tax, extracts rents from fossil resource stocks. Rent extraction is frequently recognized as a distributional issue: the political feasibility of climate policy depends on the possibility to compensate fossil resource owners. ${ }^{2}$ However, the focus on rent distribution has meant that the original motivation for rent taxation - that it may be non-distortionary and thus efficient - has not been re-assessed for the case of climate policy. Under carbon pricing, fossil resource stocks are becoming less attractive as an asset for investment, but their supply remains unchanged. Consequently, additional funds become available for alternative investments, leading to a larger overall supply of productive factors.

This paper specifically proves that pricing the flow of carbon emissions induces a beneficial macroeconomic distortion: it reduces the rents from fossil resource stocks and thus directs investment towards producible capital as the alternative asset. If capital was previously underaccumulated, this 'macroeconomic portfolio effect' constitutes a welfare improvement and lowers the gross costs of climate policy.

This result has three major policy implications: First, and most importantly, there is generally an efficiency reason for the appropriation of climate rents for the public, rather

\footnotetext{
${ }^{1}$ To limit global warming to $2{ }^{\circ} \mathrm{C}$ above pre-industrial times with a probability of at least a $66 \%$, cumulative global carbon emissions have to be less than $1000 \mathrm{GtCO}_{2}$ in this century (IPCC, 2013, p.27).

${ }^{2}$ See for example Asheim (2012); Kalkuhl and Brecha (2013); Bauer et al. (2013). Other options for spending the significant revenues have also been discussed, such as the reduction of public deficits, or of distortionary (labor) taxes (Rausch, 2013, Carbone et al., 2012, Goulder, 2013, Siegmeier et al., 2017).
} 
than only a distributional motive. It may be necessary to collect the rents to implement the socially optimal allocation. This contradicts the common perception of a trade-off between climate policy and capital accumulation (or growth) and may thus facilitate the introduction of a substantial price on carbon. Second, dynamic effects on stocks matter for the efficiency of flow-oriented climate policy instruments. Third and specifically for climate policy implemented as a permit scheme, efficiency improvements due to rent appropriation are an additional reason why permits should not be allocated for free.

Furthermore, the prominent role of rents from non-producible stocks in our analysis suggests an alternative climate policy instrument based on private property rights to the 'stock of the atmosphere': tradable rights to perpetually obtain a certain fraction of annual emission allowances. It has the same aggregate effects as conventional carbon pricing mechanisms, but two potential advantages in realistic settings: the potential for a macroeconomic portfolio effect increases with the amount of investment opportunities in both asset classes. Newly created atmospheric property rights may be more widely available to private investors than fossil resource stocks (see below). Additionally, atmospheric property rights could make environmental limitations (and revenues from climate policy) more visible to individuals, thus enhancing environmental awareness.

We use a specific formal model and policy instrument, namely a two-asset overlappinggenerations (OLG) model and an emission permit scheme, to prove the main result. We also discuss the robustness of our findings regarding alternative modeling assumptions or instrument choices. However, this specific model should also be interpreted as an illustration of the more general idea of a beneficial macroeconomic portfolio effect due to rent collection via climate- and resource policy. This general idea is based on three major assumptions:

First, we assume that capital is suboptimally underaccumulated. This seems generally plausible if capital is broadly defined to include physical as well as human capital.

Second, the investment choice between capital and fossil resource stocks requires that both types of assets are available for private investment and trade in the economy under consideration. This may be the case for countries with both substantial fossil resources and 
capital goods on their territory $\left.\right|^{3}$ Further, it can be the case for the world economy when considering rent collection as a global carbon pricing scheme. Private access to emissionrelated assets and their tradability also depends on the climate policy instrument chosen: for example, if the right to perpetually obtain a certain share of annual (national or global) emission rights was a tradable asset, the distribution of property rights to fossil resources would be less important for the portfolio effect to occur. We discuss such an instrument, related to a suggestion by McKibbin and Wilcoxen (2002), in Section 4

Third, we consider a situation where long-term climate policy has already been imposed and the economy has adapted to it. We thus neglect the anticipation and transition effects of introducing a carbon price and instead compare economic aggregates on balanced paths, focusing on how much of the rents are collected..$^{4}$

We relate our main result to three fields of research:

First, Bento and Jacobsen (2007) model a fixed factor used in the production of dirty goods, and assume that the resulting rents are (partially) untaxed. Then, levying an environmental tax that implicitly acts as a tax on these rents and using the revenues to cut distortionary labor taxes is preferable to lump-sum redistribution. It may even imply negative gross costs of the policy package because it improves an initially inefficient tax system. See Bovenberg (1999) for an overview of previous results on such 'double dividends', and Goulder (2013) for climate policy implications. While the effect presented below also stems from the collection of rents from a fixed factor, it is independent of a preexisting distortionary and inefficient tax system. Instead, welfare is increased if dynamically inefficient savings behavior is addressed: using a climate policy instrument that collects the rents related to the use of fossil resources to finance a given public revenue requirement is preferable to lump-sum taxation because it stimulates alternative, productive investment. The effect is unambiguously welfare-enhancing if capital is otherwise underaccumulated. Moreover, it is independent of the recycling of the policy's revenues $5^{5}$

\footnotetext{
${ }^{3}$ Even when the state owns most fossil resources, what matters for the potential strength of the effect is the amount of the remaining privately-held fossil assets relative to the private capital stock (Section 3.4).

${ }^{4}$ This is relevant for cases such as the European Emissions Trading System (EU ETS), where permits were initially allocated for free, and auctioning was introduced gradually and without full prior anticipation.

${ }^{5}$ However, it can be shown that the social optimum as defined by Calvo and Obstfeld (1988) can be reached if rent taxation is sufficient to finance both technical progress offsetting resource depletion and a redistribution scheme that addresses imperfect altruism between generations, the root cause of
} 
Second, our contribution is related to results on non-environmental optimal rent taxation. The basic insight goes back to Feldstein (1977): a tax on rents from a fixed factor such as land generally is distortionary, since it directs investment away from land and towards capital. Petrucci (2006) and Koethenbuerger and Poutvaara (2009) noted that this distortion is beneficial if capital was previously underaccumulated, for example due to imperfect intergenerational altruism. Edenhofer et al. (2015b) provided a formal proof and found that some forms of revenue recycling can establish the social optimum. Although Feldstein (1977) already suggested that his findings would apply to resource rent taxation (p.356), we are not aware of any work on this related to environmental policy.

Although rents in the context of climate policy did recently receive some attention (Fullerton and Metcalf, 2001; Bauer et al., 2013; Carbone et al., 2012), previous studies focused on the size of and spending options for revenues of climate policy, while the macroeconomic effects of raising such revenues have been neglected. A potential reason for this is that collecting rents is still often presented as a non-distortionary source of public revenue (Segal, 2011; Mankiw, 2008, Ch. 8), despite Feldstein's findings.

Third, the present paper complements results on asset value changes due to avoided climate damages, and on resource taxation in an endogenous growth setting. Regarding the former, Karp and Rezai (2014, 2015) point out that the current value of capital assets should increase if preventing climate damages raises their future productivity, to the benefit of older agents that own most of these assets today. If younger agents with fewer assets are compensated for their mitigation costs by transfers, a Pareto improvement may be possible. In contrast, we abstract from climate damages but add fossil resource stocks as an alternative asset class to focus on the effect of climate policy on aggregate investment and welfare. Groth and Schou (2007) also consider capital and non-renewable resources as alternative assets. They emphasize that resource taxation affects resource extraction and thus long-run growth, while capital taxation does not. However, they employ a setting with a representative infinitely-lived agent in which capital accumulation is dynamically efficient. We use an OLG model in which capital accumulation is suboptimal and emphasize the effect of resource-related carbon pricing on investment behavior. underaccumulation in our model (Section 5 ). 
The remainder of this article is structured as follows. Section 2 lays out the basic model, in which households own both capital and fossil resource stocks and face carbon pricing. Section 3 presents the main result that carbon pricing induces a macroeconomic portfolio effect: the higher the share of rents that is collected, the more investment is shifted away from fossil resource stocks and towards undersupplied capital, and the higher is social welfare. This is proved for a conventional permit scheme regulating the flow of emissions. The robustness of the result to modeling assumptions, its applicability to carbon taxes and the role of fossil resources in private portfolios is discussed. Section 4 presents an alternative 'stock instrument' related to personal carbon trading schemes. Section 5 shows how the social optimum can be achieved by revenue distribution. Section 6 concludes.

\section{Basic model}

In this section, we set up a continuous overlapping generations model (Yaari, 1965; Blanchard, 1985) to study whether climate policy induces a beneficial portfolio effect. There are two assets, capital and an exhaustible resource, no bequests (which leads to capital underaccumulation), and we assume technological progress in resource efficiency which is publicly financed ${ }^{6}$ We keep brief our description of standard elements that have been developed in more detail elsewhere (Edenhofer et al., 2015b).

On the supply side, a single final good is produced from aggregate capital $K(t)$, labor $L(t)$ and extracted fossil resources $E(t)$ augmented by publicly provided technology $A(t)$. The production function exhibits constant returns to scale and diminishing marginal productivity for each input. It satisfies the Inada conditions in all arguments. The representative firm's problem is

$$
\max _{K(t), L(t), E(t)} F(K(t), L(t), A(t) E(t))-[r(t)+\delta] K(t)-w(t) L(t)-b(t) E(t)
$$

\footnotetext{
${ }^{6}$ Private investment in R\&D for resource efficiency may be insufficient due to the public good properties of knowledge (Popp et al., 2010). Including technological progress will also be analytically convenient when we analyze different forms of carbon pricing in the following sections: the resource extraction path (which is not our focus) can be neutralized by a matching resource efficiency path, to keep effective resource supply constant and thus obtain a balanced path. Then, the dependence of the balanced path on the share of rents that is collected by carbon pricing can be analyzed to obtain the main results.
} 
yielding the standard first-order conditions

$$
r(t)+\delta=F_{K}(\cdot), \quad w(t)=F_{L}(\cdot), \quad b(t)=F_{E}(\cdot),
$$

with $r$ and $\delta$ denoting the interest rate and depreciation rate of private capital, $w$ the wage rate and $b$ the price of an extracted unit of the resource.

Assume for simplicity that improvements in resource productivity are linear in public investment $I_{A}$, so with R\&D investment efficiency $\theta$ and $\dot{A}(t)=\mathrm{d} A(t) / \mathrm{d} t$,

$$
\dot{A}(t)=\theta I_{A}(t) A(t)
$$

On the demand side, let $\phi$ be the birth rate, equal to each individual's instantaneous probability of death. Thus $\phi$ is also the death rate in the entire population (population size is constant and normalized to one) and individuals' lifetimes are exponentially distributed. If, for individuals born at time $\nu$, some age-dependent variable at time $t$ has a value $x(\nu, t)$, its aggregate (population) value is denoted by the capital letter, and

$$
X(t)=\int_{-\infty}^{t} x(\nu, t) \phi e^{-\phi(t-\nu)} \mathrm{d} \nu
$$

At time $t$, an individual born at $\nu \leq t$ has expected lifetime utility

$$
u(\nu, t)=\int_{t}^{\infty} \ln c(\nu, \tau) e^{-(\phi+\rho)(\tau-t)} \mathrm{d} \tau
$$

with consumption $c(\nu, t)$ and rate of pure time preference $\rho$. The individuals' budget identity is

$$
\begin{aligned}
\dot{k}(\nu, t)+p(t) \dot{s}(\nu, t)+c(\nu, t) & =r(t) k(\nu, t)+[(1-T(t)) b(t)-p(t)] e(\nu, t)+ \\
& +w(t)-z(t)+\phi[k(\nu, t)+p(t) s(\nu, t)]
\end{aligned}
$$

69 Individuals own capital $k$, on which they earn interest at rate $r$, and an amount $s$ out of the total (exhaustible) fossil resource stock $S$, which they can sell or buy at a price 
$p$. Alternatively, they can extract an amount $e$ at zero cost and sell it at price $b$, but have to surrender a share $T$ of the revenue to the regulator. We assume that the resource stock is homogeneous and that all resource deposits are known (and fully owned), thus abstracting from new discoveries and changes in extraction technologies. Each individual receives the same wage $w$ and potentially pays a lump-sum tax $z$ (in Section 5, we discuss the consequences of age-dependent transfers for social welfare). There are no bequest motives, but a competitive, no-cost life insurance sector to close the model: the insurance continuously obtains the assets of individuals that just died and recycles them to individuals that are still alive, in the form of annuities and transfers of land and in proportion to the assets that individuals hold, reflected by the term $\phi[k+p s]$. Since the annuity and land received in advance enters each individuals accounting while the transfer to the insurance after death does not, the changes in resource ownership of all living generations after accounting for extractions do not sum to zero:

$$
\int_{-\infty}^{t} \dot{s}(\nu, t) \phi e^{-\phi(t-\nu)} \mathrm{d} \nu+E(t)=\phi S(t) .
$$

The total resource stock $S$ evolves according to

$$
\dot{S}(t)=-E(t) .
$$

Finally, the individual also respects a solvency condition:

$$
\begin{array}{ll} 
& \lim _{\tau \rightarrow \infty}[k(\nu, \tau)+p(\tau) s(\nu, \tau)] e^{-R(t, \tau)}=0 \\
\text { with } & R(t, \tau) \equiv \int_{t}^{\tau}(r(\tilde{t})+\phi) \mathrm{d} \tilde{t} .
\end{array}
$$

The government always collects a share $T$ of the (resource) rent and instantaneously invests it, together with potential revenues from lump-sum taxes $z$, into technological progress offsetting the decreasing supply of fossil fuels. The government's budget identity thus is

$$
T(t) b(t) E(t)+Z(t)=I_{A}(t) .
$$




\section{Main result: the beneficial portfolio effect of carbon} pricing

In this section, we prove that carbon pricing may induce a beneficial macroeconomic portfolio effect. For this, we compare two ways of financing a given public revenue requirement: a lump-sum tax and carbon pricing as a means to collect rents. Lump-sum taxation does not affect capital underaccumulation, while collecting scarcity rents from resource stocks makes investing in capital relatively more attractive, which enhances efficiency and welfare.

This basic effect occurs for all forms of carbon pricing. Here, we specifically assume that climate policy is implemented as a short-term, upstream emission trading scheme. This simplifies the exposition because the path of resource extraction and thus greenhouse gas (GHG) emissions is exogenously given by the amount of permits over time, and the degree of rent collection is controlled separately by the exogenously given share of permits that is auctioned.

First, we detail the policy and solve the model introduced in Section 2, Second, we characterize balanced paths on which capital and consumption stay constant while regulated resource depletion and $\mathrm{R} \& \mathrm{D}$ for resource efficiency improvements offset each other. Third, we compare pure lump-sum R\&D funding to an auctioning of permits (or a tax on extraction revenues) on balanced paths. Fourth, we discuss some assumptions underlying our modeling of a permit scheme, the applicability of the analysis to carbon taxes, and the role of the share of fossil assets in private portfolios.

The next two sections will then discuss another alternative instrument and the possibility to reach the social optimum.

\subsection{Government policy, individual optimization and aggregate dynamics}

The government limits GHG emissions by continuously issuing permits for fossil resource extraction 7 Permit lifetimes are short relative to the total time horizon over which GHG

\footnotetext{
${ }^{7}$ Extraction permits are equivalent to issuing permits for the amount of $\mathrm{CO}_{2}$ emissions that the use of
} the extracted resource will cause, but they simplify exposition here because we do not need to model two 
221

ocks (permits and fossil resources).

${ }^{8}$ Non-exponential mitigation paths can also be accommodated: the crucial assumption for reaching an analytical solution is that technological progress can keep effective resource supply constant. See Section 3.4 for a discussion.

$$
E(t) \leq \bar{E}(t)=E_{0} e^{-\sigma t} .
$$

We assume that this constraint is binding at all times, i.e. that unregulated extraction rates would exceed the maximum permissible extraction rate $\sigma$. Thus, replacing the total resource stock dynamics (8), we have

$$
\dot{S}(t)=-\bar{E}(t) .
$$

Using Equation (11) and setting $\lim _{t \rightarrow \infty} S(t)=0$ for simplicity (implying full extraction of the initial quantity $\left.S_{0}\right)$, we thus obtain $\bar{E}(t)=\sigma S(t)$ and $E_{0}=\sigma S_{0}$. A similar relationship holds for individuals, who do not choose $s$ and $e$ separately: even if there are several different resource stocks, their combination in individuals' portfolios is identical across homogeneous households. Thus, the ratio of individual resource extractions $\bar{e}(\nu, t)$ to the aggregate admissible extraction $\bar{E}(t)$ equals the ratio of individual resource ownership $s(\nu, t)$ to the total resource stock $S(t)$, and $\bar{e}=\bar{E} s / S=\sigma s$. Suppressing time dependencies, we can then rewrite the budget constraint (6) as

$$
\dot{k}+p \dot{s}+c=w+r k+[(1-T) b-p] \sigma s-z+\phi(k+p s) .
$$

The share $T$ of rents from resource extraction can be interpreted as an ongoing auctioning of a share $T$ of permits and free allocation of the remaining permits, or equivalently, as initial free allocation of all permits followed by a tax on revenues from resource extraction. 
Individuals maximize utility (5) by choosing paths for $c$ and $s$, subject to budget identity (61) and solvency condition (9). From the first-order conditions of this optimization problem, one obtains the usual Keynes-Ramsey rule for the dynamics of individual consumption (Appendix A.1)

$$
\frac{\dot{c}(\nu, t)}{c(\nu, t)}=r(t)-\rho
$$

and a no-arbitrage condition between the resource stock and capital:

$$
\frac{\dot{p}(t)}{p(t)}=r(t)+\frac{p(t)-[1-T(t)] b(t)}{p(t)} \sigma .
$$

The last term reflects the effect of exogenously imposing the resource extraction path on the resource stock price dynamics.

Using the Keynes-Ramsey rule and the no-arbitrage condition together with the budgetand solvency conditions, it can be shown that each individual consumes the same fixed fraction of her total wealth, consisting of capital, fossil resources and lifetime labor income net of taxes (Appendix A.1):

$$
\begin{aligned}
c(\nu, t) & =(\rho+\phi)[k(\nu, t)+p(t) s(\nu, t)+h(t)] \\
\text { with } \quad h(t) & \equiv \int_{t}^{\infty}[w(\tau)-z(\tau)] e^{-R(t, \tau)} \mathrm{d} \tau .
\end{aligned}
$$

We can now derive the remaining aggregate demand-side quantities according to (4) (see Appendix A.2). From Equations (14) and (7), aggregate consumption is the same constant fraction of total wealth as for each individual:

$$
C(t)=(\rho+\phi)[K(t)+p(t) S(t)+H(t)]
$$

For the dynamics of the total capital stock, apply the definition of $K$, Leibniz' rule and the individual budget constraint $(6])$ to get

$$
\dot{K}(t)=w(t)+r(t) K(t)+b(t) \bar{E}(t)-I_{A}-C(t) .
$$


The growth rate of aggregate consumption can be derived from the definition of $C$, using Leibniz' rule and Equations (12) and (14):

$$
\frac{\dot{C}(t)}{C(t)}=r(t)-\rho-(\rho+\phi) \phi \frac{K(t)+p(t) S(t)}{C(t)} .
$$

The last term is due to the 'generation replacement effect': A share $\phi$ of the population, owning capital $\phi K$ and resource wealth $\phi p S$, dies and is 'replaced' by newborns without assets. This continuous turnover of generations of different wealth also affects aggregate consumption growth, since consumption is a fixed fraction $(\rho+\phi)$ of wealth. The effect of newborns' lack of capital and fossil resources is always negative. Note that the dynamics of aggregate quantities are independent of lump-sum taxes $Z .9$

\subsection{Balanced paths}

The differential equations for the aggregate resource stock $S$, technology $A$, the resource stock price $p$, aggregate capital $K$ and aggregate consumption $C$ describe the dynamics of the economy (Equations (81), (3), (13), (16) and (17), respectively). The price of the extracted resource $b$ and interest $r$ depend on $K, A$ and $S$ via the production function, so they do not add extra dimensions.

Denote by $I_{A}^{*}$ the research investment required to exactly offset resource depletion. Due to (3) and (11), this investment is constant:

$$
I_{A}^{*}=\sigma / \theta
$$

For simplicity, we will contrast below two polar cases of financing this R\&D level, either by permit auction revenues only, or purely by lump-sum taxation. For this reason, we assume that permit auction revenues are by themselves sufficient to finance the research investment level (18) chosen by the government to offset regulated resource depletion (11):

\footnotetext{
${ }^{9}$ If taxes or transfers are age-dependent $(z(\nu, t)$ instead of $z(t))$, a 'redistribution effect' affects the generation replacement effect. This is reflected by an additional term in the numerator of the last fraction of (17) - see Equation (A8) in Appendix A.2, and Section 5 for a discussion.
} 
See Section 3.4 for further discussion of this assumption. The inequality of course also implies that the alternative lump-sum financing of $R \& D$ is feasible in terms of potential revenues, too, since resource rents are part of each individual's lifetime income. If lumpsum taxes are politically infeasible, the consequence is a trade-off between the beneficial effect described below and distortions from other taxes, which is beyond the scope of the analysis presented here.

With exogenously given depletion (11) and R\&D investment (18) fixing the evolution of $S$ and $A$, balanced paths are described by

$$
\left\{K(t)=K^{*}, C(t)=C^{*}, S(t)=S_{0} e^{-\sigma t}, A(t)=A_{0} e^{\sigma t}, p(t)=p_{0}^{*} e^{\sigma t}\right\},
$$

where $A_{0}, S_{0}$ are given and $K^{*}, C^{*}, p_{0}^{*}$ denote the solution to the following system of equations (using Equations (2)):

$$
\begin{aligned}
& \dot{K}=0 \rightarrow \quad C_{P}(K)=F(K)-\delta K-I_{A}^{*}, \\
& \dot{C}=0 \rightarrow \quad C_{H}(K)=\phi(\rho+\phi) \frac{K+p_{0}(K) S_{0}}{r(K)-\rho}, \\
& \text { Eq.13 } \rightarrow \quad p_{0}(K)=(1-T) \sigma \frac{b_{0}(K)}{r(K)},
\end{aligned}
$$

written here with $K$ as the independent variable for convenience in the subsequent analysis ${ }^{10}$ The crucial policy parameter determining the values of $K^{*}, C^{*}$ and $p^{*}$ is the auctioned share of permits $T$, since the optimal choice of the extraction rate $\sigma$ or of the total amount of permits (represented here by the total available resource stock $S_{0}$ ) are assumed to be given.

In the following, the system is reduced to two dimensions, $C$ and $K$, by maintaining $d(p S) / d t=0$. A projection to these two variables captures all relevant dynamics (see ${ }^{10}$ For Equation 23 , we substituted $\dot{p} / p=\sigma$ in the no-arbitrage condition 13 , and used that

$$
b=F_{E}=F_{A E}(K, L, A E) A=F_{A E}\left(K, L, A_{0} E_{0}\right) A_{0} e^{\sigma t} \equiv b_{0}(K) e^{\sigma t} .
$$




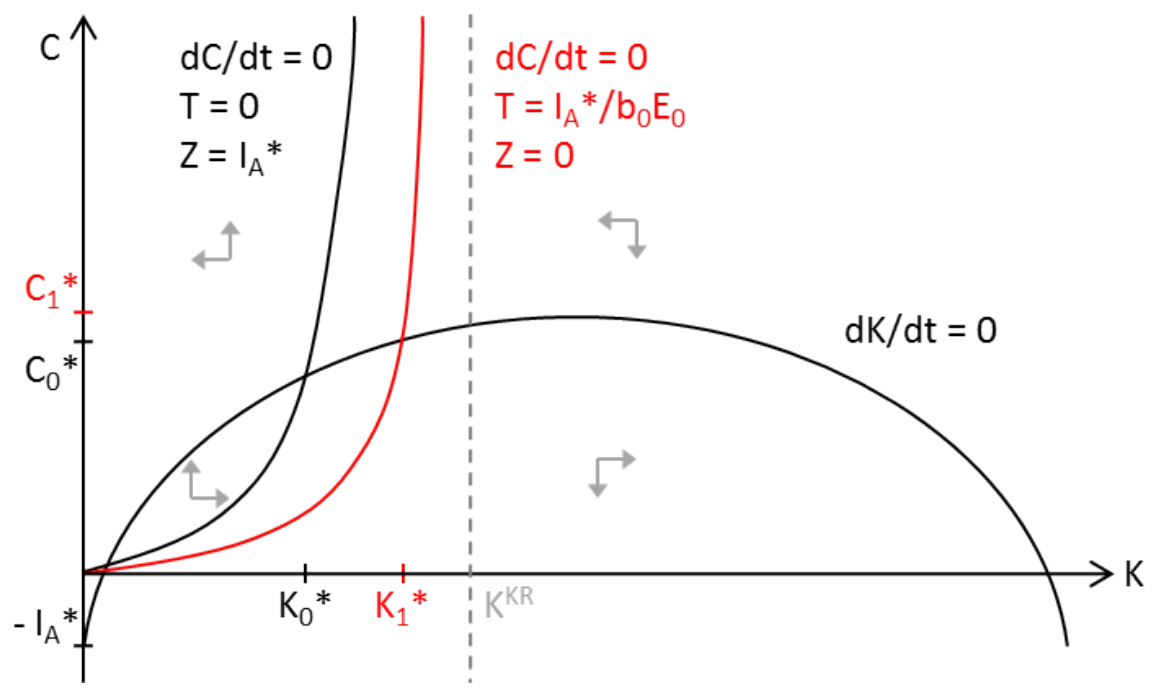

Figure 1: Phase diagram for aggregate consumption $C$ and capital $K . K^{k r}$ denotes the Keynes-Ramsey capital level, given by $F_{K}\left(K^{k r}\right)-\delta=\rho$.

Appendix A.3 - intuitively, the balanced paths above require that the value of the resource stock $p S$ is constant, because otherwise the generation replacement effect in Equation (22) is non-constant, and thus also $C$.

In the $C$ - $K$-plane, Equation (21) defines a parabola-shaped curve and Equation (22) a hyperbola (see Figure 1). The $\dot{K}=0$ locus is shifted downwards relative to the origin by $I_{A}^{*}$. We assume that $I_{A}^{*}$ is sufficiently small so that two intersections of the parabola and hyperbola exist (for empirical plausibility see Section 3.4). The values of $C$ and $K$ at each of these intersections solve the system of equations above. While the lower intersection is unstable, the upper describes the $C^{*}-K^{*}$ combination of the stable balanced path that we are interested in (Appendix A.3). In the following, we denote by an asterisk * all quantities on the stable balanced path (where all three of Equations 2123 hold). In particular,

$$
r^{*}=F_{K}\left(K^{*}\right)-\delta, \quad b_{0}^{*}=F_{E}\left(K^{*}\right) A_{0}, \quad p_{0}^{*}=(1-T) \sigma b_{0}^{*} / r^{*}
$$

\subsection{The macroeconomic portfolio effect of carbon pricing}

We now show that underaccumulation of capital due to the generation replacement effect can be mitigated by resource rent collection (here, by auctioning of emission permits), but not by lump-sum taxation. 
We first discuss why aggregate capital and consumption are suboptimally low. The reference point for social optimality are the Keynes-Ramsey steady-state levels ${ }^{11}$ of consumption $C^{k r}$ and capital $K^{k r}$, which satisfy

$$
C^{k r}=F\left(K^{k r}\right)-\delta K^{k r}-I_{A}^{*}
$$

and $\quad F_{K}\left(K^{k r}\right)-\delta=\rho$.

Equation (22) is essential for analyzing the welfare effects of rent collection, since the position of the parabola (Equation 21) does not change with $T$. Solving for the steady state interest rate and using Equations (24) yields

$$
r^{*}=\rho+\phi(\rho+\phi) \frac{K^{*}+p_{0}^{*} S_{0}}{C^{*}}=\rho+\phi(\rho+\phi) \frac{K^{*}+(1-T) \sigma S_{0} b_{0}^{*} / r^{*}}{C^{*}} .
$$

Thus, the interest rate in the decentralized economy is higher than the implied price of capital in the socially optimal steady state (Equation 26). From $F_{K K}<0$ and Equation (2) follows a lower level of capital, $K^{*}<K^{k r}$. Since $K^{k r}$ is left of the maximum of the parabola (21), a lower capital stock implies that consumption is suboptimal, $C\left(K^{*}\right)<C\left(K^{k r}\right)$.

We now discuss two policies, corresponding to the two hyperbolas in Figure 1. First, assume that there is no price on fossil resource extraction $(T=0)$ and that technological progress is financed by lump-sum taxation (the government's budget identity 10 becomes $Z^{*}=I_{A}^{*}$, leaving the aggregate dynamics unaffected). Then, the second term in Equation 27) has its maximal value, and capital accumulation and aggregate consumption attain their lowest values (since the intersection of the hyperbola and the parabola is always to the left of the maximum of the parabola).

At the other extreme, with only the collected resource rents financing technological progress $\left(T b \bar{E}=I_{A}^{*}\right.$ and $\left.Z=0\right)$, underaccumulation is reduced relative to the lump-sum tax case since the tax lowers $p_{0} S_{0}$, so ceteris paribus the second term in Equation (27) is smaller. The intuition is that the lower rent earnings make investing in the resource stock less attractive than capital investment, as reflected in the no-arbitrage condition (13), and

\footnotetext{
${ }^{11}$ This can be derived using the approach of Calvo and Obstfeld $\sqrt{1988)}$, see also Edenhofer et al. $(2015 \mathrm{~b})$.
} 
thus causes a rebalancing of the asset portfolio. Also, a lower resource stock price means less 'missing wealth' for the newborns, and thus a smaller generation replacement effect (but the effect is still non-zero for all $T$, so the social optimum cannot be reached without additional policies, see Section 50. These effects are of course not isolated, but interact via general equilibrium effects. We thus formalize and prove the effect, also allowing for combinations of both financing options.

Theorem. Suppose that the economy is on a balanced path on which publicly financed technological progress exactly offsets decreasing availability of (extraction) permits, that any share of these permits may be auctioned or allocated for free, and that lump-sum payments are available. Then, the higher the share of permits that is auctioned, the higher is social welfare.

This result is proved in Appendix A.4 by showing that the higher the auctioned share of permits $T$, the higher are aggregate capital and consumption. The basic message is that it is welfare-enhancing to fulfill the revenue requirement for R\&D investment by distortionary auctioning of permits instead of fulfilling it by non-distortionary lump-sum taxation (which should only close a potential gap if revenues from full auctioning are insufficient). However, the theorem is stronger: It implies that even if the revenue requirement can be fulfilled without auctioning all permits, it is still desirable to auction permits to the largest degree possible for efficiency reasons. Revenues in excess of R\&D investment needs are redistributed here by a lump-sum transfer that is uniform across all generations; other transfer schemes are explored in the next subsection.

As a direct consequence of the theorem above, the gross costs of climate policy are reduced if permits are auctioned.

\subsection{Generalizations and importance of the effect}

The main result above was obtained for an implementation of carbon pricing by a specific emission trading scheme. We first discuss the credibility of our assumptions made in modeling this specific scheme. Second, we examine the occurrence of the macroeconomic portfolio effect under alternative implementations of carbon pricing by carbon taxes. Third, 
we discuss how the share of fossil fuel assets in private investors' portfolios affects the importance of the effect.

\section{Modeling assumptions}

We begin by justifying specific modeling choices about the emission trading scheme that made our model tractable. We equated short permit lifetimes with direct control of the emission path, required public financing of resource efficiency improvements, chose a specific shape of the permissible extraction path and assumed that long-term climate policy has been credibly imposed. We now discuss the restrictiveness of the underlying assumptions in turn.

Regarding permit lifetimes, we emphasize that what matters for climate protection are the cumulative GHG emissions over longer periods (several decades), not their short-term path (Meinshausen et al., 2009, Ciais et al., 2013). However, practical implementations of climate policy via emission trading schemes, such as the EU ETS and the California Cap-and-Trade scheme, operate on relatively short time scales, with emissions budgeted over trading periods of eight and three years, respectively 12 Thus, when endogenous emissions are limited to short time horizons, a succession of many short-term budgets can be approximated well by a fixed path. The fixing of such a long-term mitigation path by the government is not necessarily less efficient than a decentralized solution, depending e.g. on whether individual agents or the government are myopic or not.

Next, we require public financing of resource efficiency improvements: We use publiclyfinanced R\&D to underline (a) the necessity of R\&D to counter mitigation-induced scarcity, and (b) that even if the mitigation path is given, the government still has a choice regarding R\&D investment. The government's optimization problem that should determine this choice is not modeled here: completely offsetting resource scarcity and maintaining a steady state via R\&D is chosen merely for simplicity. Furthermore, public investment in resource efficiency improvements could be interpreted to also include investment in infrastructure

\footnotetext{
${ }^{12}$ Forward 'banking' of unused permits between trading periods is generally allowed (and is beneficial when the supply of new permits is successively tightened (Rubin, 1996)), but can be neglected if we assume that emission budgets are a binding constraint. More importantly, 'borrowing' of permits to delay mitigation is not possible in California, and restricted to within a trading period in the EU.
} 
that matches resource-efficient technologies, such as railways, bike lanes, or electricity grids and system services required for integrating electricity generation from fluctuating renewable sources. 13

Furthermore, we chose a specific shape of the permissible extraction path, and resource efficiency improvements: for simplicity, we chose an exponentially declining extraction path $\left(E(t)=E_{0} e^{-\sigma t}\right)$, and accordingly assumed that R\&D investment translate into resource efficiency improvements as $\dot{A}=\theta I_{A} A$, so that $I_{A}=\sigma / \theta$ leads to $A(t) E(t)=$ const. An exponential extraction path is analytically convenient, but the exact shape of the path is irrelevant for our results as long as technological progress is such that spending no more than a certain fraction of output on $R \& D$ can offset the decreasing resource supply (see Bretschger (2005) for a discussion). This assumption about technology, at times considered optimistic, is not crucial and only employed here to obtain an analytical solution ${ }^{14}$

Moreover, our analysis starts after long-term climate policy has been credibly imposed (see also Footnote 4): economic actors know and have adapted to the paths for total and auctioned amounts of permits, so it is sufficient to compare balanced paths with different auctioned shares. We do not model the transition to these balanced paths after climate policy is first announced, including the initial one-off devaluation of fossil resource stocks that cannot be exploited anymore $\sqrt{15}$ It is important to note that the assumption of an exogenous and binding cap that tightens over time means that our model abstracts from real-word complications regarding commitment and credibility. In political practice, interest groups can be expected to exert pressure on the government to loosen the cap if

${ }^{13}$ We further assume that to finance public spending on R\&D, climate policy revenues can be topped up by lump-sum taxes if necessary. This is analytically convenient because we focus on rent taxation. Introducing distortionary taxation as an additional source of public funds, as for example in Turnovsky (2000), will not change the basic mechanism.

${ }^{14}$ Investments $I_{A}^{*}$ can be assumed to be significantly smaller than the mitigation costs of climate change, because these also comprise forgone consumption due to costly transformation of the capital stock (e.g. different power plants). In turn, the costs of climate change mitigation are very small compared to aggregate output or capital (in the order of 0.04 to 0.14 percentage points of reduction of annual consumption growth (IPCC, 2014)). Conceptually, our assumptions about the size of $I_{A}$ are distinctively un-Malthusian, because they insure that the transformation of the economy to a low-carbon state is possible at little cost and without disturbing stability.

${ }^{15}$ The total number of permits relative to the demand for emissions determines the scarcity and thus the total price of the permits; their total number relative to the size of the remaining fossil resource stocks determines the losses faced by the owners of those stocks when the permit scheme is first introduced. Kalkuhl and Brecha (2013) and Bauer et al. (2013) analyze the potential for compensating the owners of fossil resource stocks from carbon pricing revenues, and Koethenbuerger and Poutvaara (2009) and Heijdra et al. (2006) consider transition effects of introducing a tax on a fixed factor or pollution, respectively. 
resource- or carbon prices increase. Further, how firms will plan in the face of policy uncertainty about changes to the cap and what this implies for climate policy instrument choice is underexplored (however see Salant (2016) and Koch et al. (2016)). The behavior of market participants under such policy uncertainty and attempts to influence the government would not generally change the main message of the present article. However, it is crucial to be mindful that the assumption of an exogenous, binding and gradually tightening cap abstracts from such issues.

\section{Applicability to carbon taxes}

As an alternative to a permit scheme, a carbon price may be implemented by a carbon tax. In our setting, the main difference is that extraction is determined endogenously. Nevertheless, a carbon tax can be expected to also induce a (beneficial) portfolio effect: as for a permit scheme, the basic intuition is that a carbon tax always extracts some part of the fossil resource rent, reduces returns from fossil resource assets and thus makes saving in (previously underaccumulated) producible capital relatively more attractive. Indeed, farbon tax schemes can fully replicate emission permit schemes (see also Fullerton and Metcalf, 2001), both in terms of climate change mitigation and rent collection.

Under an emission permit scheme, the amount of emission reductions and the collected share of rents can be chosen separately via the size of the cap and the auctioning rate of the permits. While a carbon tax has no direct control over emissions and extractions, it may still affect them in two ways, which in turn also affect rent collection: First, if a carbon tax that acts as a tax per unit of the extracted resource grows at a rate below the discount rate, there is an incentive to postpone emissions and resource extraction, because a higher share of rents can be privately retained in the future. This also implies an upper limit on the degree of rent collection that is consistent with a given level of climate change mitigation by this 'postponement effect', and a trade-off between further rent collection and mitigation beyond that. However, this constraint may not be binding if higher degrees of rent collection are politically infeasible anyway. Second, there is a 'volume effect' (Edenhofer and Kalkuhl, 2011) that can alleviate it: if the effective tax per unit of the extracted resource is above the scarcity price (minus extraction costs), 
demand will be reduced and some resources may be left in the ground, while $100 \%$ of the rent are collected. In sum, with these two effects one may expect that any desired level of mitigation could be implemented in our setting. Additionally, some of the tax revenues could be used to partly compensate resource owners and adjust any level of rent collection below $100 \%$ without compromising mitigation, thus fully replicating a permit scheme ${ }^{16}$ However, formally proving this would require to include into our OLG model a more detailed description of endogenous resource extraction as in Edenhofer and Kalkuhl (2011), which is beyond the focus and scope of this paper ${ }^{17}$

\section{Private investment in fossil resources}

The potential for a beneficial portfolio effect importantly depends on the share of fossils stocks in private investors' portfolios: according to Equation (17), the portfolio share equals the maximum share of the generation replacement effect that can be neutralized by rent collection. Battiston et al. (2017) estimate that in the EU and the USA, fossil fuels have a portfolio share of $4-7 \%$, depending on the type of private investor 18 This share may seem small at first, but it does not imply that the macroeconomic portfolio effect is small or unimportant, too, for three reasons:

First, neutralizing a given share of missing wealth does not translate linearly into realizing the same share of maximally possible welfare gains, as Equations $(21)-(23)$ and Figure 1 show.

\footnotetext{
${ }^{16}$ Another possibility to reduce the rent collection share is to apply the carbon tax only to emissions above a threshold, in analogy to a free allocation of emission permits (Mumy, 1980, Pezzey and Jotzo, 2012 ).

${ }^{17}$ In practice, carbon taxes are generally implemented as unit taxes (World Bank et al., 2016) with postponement- and volume effects. These are not in general amenable to our analytic approach based on balanced paths (see Appendix A.5), but may instead require numerical modeling. Appendix A.5 describes an analytically simpler form of a carbon tax, namely an ad valorem tax, under which a volume effect cannot occur. We can then prove a corollary of the theorem in Section 3.3 for a constant tax rate that also has no postponement effect (Dasgupta and Heal, 1979). Such a tax only indirectly induces some climate change mitigation, because the portfolio effect leads to a lower interest rate, so extraction is slower. A unit tax will only be similarly extraction-neutral if it starts from a low value and grows at the resource owners' discount rate. However, even the optimal growth rate for a unit tax suggested by integrated assessment models is lower than that (Edenhofer and Kalkuhl, 2011).

${ }^{18}$ Similarly to the portfolio effect between fossils-based assets and capital described here, a redirection of investments can also be expected among producible capital assets when climate policy makes fossil fuel-dependent utilities and energy-intensive industries less attractive. This is plausible in particular to the extent that these industries generate rents based on very long-lived, sunk investments. We note that utilities and energy-intensive industries account for 1-3\% and 21-28\% of private portfolios, respectively (Battiston et al., 2017).
} 


\footnotetext{
${ }^{19}$ According to the IEA (2014), states or state-owned companies together control more than $70 \%$ of global oil and gas reserves, as well as $9 \%$ of hard coal production capacity in the OECD and $66 \%$ outside the OECD.
} 
potential advantage (beyond the one above).

We suggest a stock instrument for climate policy with the following structure: Assume that households own shares $s_{a}$ of the atmosphere (instead of shares of fossil resource stocks). Ownership of such shares entitles them to annually obtain emission rights, the amount of which decreases at rate $\sigma$. Households can sell these emission rights to firms at a price $l$ and pay taxes on the revenues (they 'rent out' their share of the atmosphere to the firms). They can also trade the shares among each other. Our suggestion is related to the „long-term permit' component of the McKibbin-Wilcoxen hybrid climate policy (McKibbin and Wilcoxen, 2002), which those authors also allow to embody declining annual emission rights (McKibbin and Wilcoxen, 2007; McKibbin, 2012) ${ }^{20}$ However, this type of permit system has not been considered in an analytical model before the present article. It is also related to the case of 'exogenously shrinking' land considered by Buiter $(1989)$ in the context of debt neutrality of taxation of fixed factors.

For this alternative instrument, the model presented in Section 2 is modified as follows: The individual budget becomes

$$
\dot{k}+p \dot{s}_{a}+c=w+r k+[(1-T) l-p \sigma] s_{a}-z+\phi\left(k+p s_{a}\right) .
$$

Here the term $-p \sigma s_{a}$ comes from the annual decrease in emission rights attached to the ownership of an atmospheric stock. The dynamics of the atmospheric stock are controlled by the government and, as above, taken to be

$$
\frac{\dot{S}_{a}}{S_{a}}=-\sigma .
$$

Its decreasing availability reflects the limited disposal space for emissions. Still, $\dot{S}_{a}=-E$, so that $E=\sigma S_{a}$. So $\sigma$ is both the rate of decline of the atmospheric stock and the ratio between emissions used and total available space in the atmosphere. In particular, while households rent out their share of the atmosphere to the firm for one year, $E$ denotes the

\footnotetext{
${ }^{20}$ The nature of the 'long-term permits' is not central to the major advantages of the hybrid climate policy propounded by McKibbin and Wilcoxen (2002). In McKibbin and Wilcoxen (2007), the authors attribute the suggestion of embodying declining emission rights into a long-term permit to Rob Stavins, while in McKibbin (2012) some advantages to this specific design are briefly mentioned, see also below.
} 


$$
l=F_{S_{a}}\left(K, L, A E\left(S_{a}\right)\right)=F_{E}\left(K, L, A E\left(S_{a}\right)\right) \sigma .
$$

One more modification concerns Equation (7), which has to be changed to

$$
\int_{-\infty}^{t} \dot{s}(\nu, t) \phi e^{-\phi(t-\nu)} \mathrm{d} \nu-\sigma S(t)=\phi S(t),
$$

as the atmospheric stock shrinks without being used. The remaining defining equations of the model are identical. The only change to the resulting dynamics of the economy is that the no-arbitrage condition is now between the atmospheric stock and capital:

$$
\frac{(1-T) l}{p}+\frac{\dot{p}}{p}=r+\sigma
$$

Thus, the stock instrument will be equivalent to the conventional permit scheme if $l=b \sigma$, which holds by Equation (28). Intuitively, renting the stock of the atmosphere $S_{a}$ at rate $l$, or buying a flow of resources $\bar{E}=\sigma S$ at price $b$, must have the same value to firms, so the original and modified budget equations are the same. The deeper reason for this equivalence is that our model of the flow-based permit scheme above already contained the core of the stock instrument, which is to treat $e$ as proportional to $s$ and thus to prevent endogenous extraction dynamics.

While the stock- and flow permit schemes are formally equivalent in our model of a closed, competitive economy, where everyone owns resources (or parts of the atmosphere), differences may arise in more realistic settings. ${ }^{21}$

First, as discussed in Section 3.4, private investors may have limited access to fossil resource assets. A stock instrument replaces them with more widely available assets (claims to parts of the atmosphere), thereby increasing the potential for a beneficial portfolio effect compared to a flow permit scheme.

\footnotetext{
${ }^{21}$ The two instruments seem to imply different distributions: While considering the fossil resource stocks underlying an emission trading scheme evokes that 'only resource owners' possess such assets, introducing a new property structure is associated with the idea that 'everyone gets permits'. However, an initial or perpetual reallocation of shares of the stock is in principle possible for both instruments, so differences between them do not arise primarily from different distributions.
} 
Second, a standard argument against implementing climate policy by an emission trading system is that it crowds out social preferences, namely personal motivation to behave in an environmentally-friendly way (Frey, 1999; Bowles and Polania-Reyes, 2012). An alternative climate policy could attempt to make the scarcity of carbon sinks more tangible to individuals, and provide them with an opportunity to express social preferences directly and visibly for others. A consequence of such a policy may be greater political support for introducing or tightening a cap on emissions (see also McKibbin, 2012). This has been the chief motivation behind the idea of personal carbon trading (PCT) schemes (Hillman, 1998; Fleming, 1997; Fawcett, 2010) to which our suggestion of a 'stock instrument' is related. While PCT only differs from conventional emission trading systems by regulating emissions directly at the level of the households, our proposed stock instrument would additionally give households some 'property rights to the atmosphere', with ensuing changes in investment decisions. Whether such a policy may enhance environmental awareness and may be more socially acceptable than conventional emissions trading is a question for future research.

\section{Non-uniform revenue redistribution: social optimal- ity and compensations}

We discuss two extensions on revenue use for the case that climate policy revenues exceed R\&D financing requirements. These excess revenues may then be recycled in the form of age-dependent transfers. If such transfers favor individuals without wealth (the newborns and young, in our case), they may establish the social optimum. Alternatively, if they partly or fully compensate resource owners (older individuals) for their tax payments, this reduces or neutralizes the beneficial portfolio effect.

If resource revenues exceed required $\mathrm{R} \& \mathrm{D}$ investments $\left(T^{*}<1\right)$, it can be seen from Equations (22), (23) and (27) that raising the auctioned share above $T^{*}$ further reduces the value of the fossil resource and the interest rate, and increases the capital stock and consumption. But due to the missing capital wealth $\phi K$ of the newborns, the generation replacement effect never fully disappears by this price effect alone, even if $T$ approaches 1 


\footnotetext{
${ }^{22}$ Technically, age-dependent transfers imply an additional term in the generation replacement effect in Equation (17) - Appendix A.2 provides the more general form (Equation A8). This additional term is negative for redistributive transfers that are biased towards the young, offsetting their missing capital.

The price- and redistribution effect together may even lead to overaccumulation. Thus, the optimal auctioning share, which can be shown to be

$$
T^{o p t}=\frac{\phi\left(K^{*}+p_{0} S_{0}\right)+I_{A}^{*}}{b_{0} \sigma S_{0}}=\frac{\phi\left(r^{*} K^{*}+b_{0} \sigma S_{0}\right)+r^{*} I_{A}^{*}}{\left(r^{*}+\phi\right) b_{0} \sigma S_{0}},
$$

may be smaller than one. This also implies a condition for reaching the social optimum: When the (gross) value of the extracted resource $b \sigma S$ exceeds the total missing (net) wealth of all newborns $\phi(K+p S)$ (plus investments $I_{A}$ into resource efficiency improvements), the social optimum can be implemented by collecting less than $100 \%$ of the rents and redistributing them to the newborns.
} 
The present article therefore has studied the impact of climate policy on aggregate investment behavior, and identified a beneficial effect. For a conventional emission trading system, auctioning of permits was proved to induce a shift of investment away from fossil resource stocks towards producible capital. If capital is underaccumulated - a plausible assumption if capital is broadly conceived and includes human capital - this 'macroeconomic portfolio effect' increases efficiency and thus social welfare. The effect implies that the gross costs of climate policy are lower compared to cases in which rent extraction is allocation-neutral, and provides a new reason for the old conclusion that permits should not be allocated for free.

We showed that the macroeconomic portfolio effect is robust to variations in the modeling of the permit scheme, and indicated that it also holds for carbon pricing implemented by a carbon tax. If imperfect intergenerational altruism is the source of capital underaccumulation, using the revenues from rent-extracting policies to the benefit of the young may even establish the social optimum.

Furthermore, the portfolio effect relies on the assumption that private investors can buy and trade non-negligible amounts of fossil resources. If this is not the case, and in particular in settings with several countries or classes of agents with different resource endowments, a 'stock-based' scheme that introduces ownership of a share of perpetually renewed emission rights may offer a remedy: while being formally equivalent to the conventional permit scheme, the new asset may be available at a larger volume and more liquid. Furthermore, environmental awareness and political feasibility of stringent climate policy could be enhanced by distributing atmospheric property rights instead of implementing an upstream emissions trading system.

In sum we have thus confirmed Feldstein's conjecture regarding resource rents and showed how it applies to climate policy. Extracting resource rents has dynamic investment effects, and since these increase efficiency, resource rent extraction is desirable not only for distributional reasons. Going beyond climate economics, our results support the view of Stiglitz (2016a b) that rents and their taxation are pivotal to understanding and addressing current trends of growth and distribution. 


\section{References}

Asheim, G. B., 2012. A distributional argument for supply-side climate policies. Environmental and Resource Economics 56(2), 239-254.

Battiston, S., Mandel, A., Monasterolo, I., Schutze, F., Visentin, G., 2017. A climate stress-test of the financial system. Nature Climate Change 7, 283-288.

Bauer, N., Mouratiadou, I., Luderer, G., Baumstark, L., Brecha, R. J., Edenhofer, O., Kriegler, E., 2013. Global fossil energy markets and climate change mitigation - an analysis with ReMIND. Climatic Change pp. 1-14.

Bento, A. M., Jacobsen, M., 2007. Ricardian rents, environmental policy and the double-dividend hypothesis. Journal of Environmental Economics and Management 53(1), 17-31.

Blanchard, O. J., 1985. Debts, deficits, and finite horizons. Journal of Political Economy 93(2), 223-247.

Bovenberg, A. L., 1999. Green tax reforms and the double dividend: an updated reader's guide. International Tax and Public Finance 6(3), 421-443.

Bowles, S., Polania-Reyes, S., 2012. Economic incentives and social preferences: substitutes or complements? Journal of Economic Literature 50(2), 368-425.

Bretschger, L., 2005. Economics of technological change and the natural environment: How effective are innovations as a remedy for resource scarcity? Ecological Economics 54(2-3), 148-163.

Buiter, W. H., 1989. Debt neutrality, Professor Vickrey and Henry George's single tax. Economics Letters 29(1), 43-47.

Calvo, G. A., Obstfeld, M., 1988. Optimal time-consistent fiscal policy with finite lifetimes. Econometrica $56(2), 411-432$.

Carbone, J. C., Morgenstern, R. D., Williams III, R. C., 2012. Carbon taxes and deficit reduction. Working paper.

Ciais, P., Sabine, C., Bala, G., Bopp, L., Brovkin, V., Canadell, J., Chhabra, A., De Fries, R., Galloway, J., Heimann, M., Jones, C., Le Qur, C., Myneni, R., Piao, S., Thornton, P., 2013. Carbon and other biogeochemical cycles. In: Stocker, T., Qin, D., Plattner, G.-K., Tignor, M., Allen, S., Boschung, J., Nauels, A., Xia, Y., Bex, V., Midgley, P. (Eds.), Climate Change 2013: The Physical Science Basis. Contribution of Working Group I to the Fifth Assessment Report of the Intergovernmental Panel on Climate Change, Cambridge University Press.

Dasgupta, P., Heal, G., 1979. Economic Theory and Exhaustible Resources. Cambridge University Press, Cambridge.

Edenhofer, O., Jakob, M., Creutzig, F., Flachsland, C., Fuss, S., Kowarsch, M., Lessmann, K., Mattauch, L., Siegmeier, J., Steckel, J. C., 2015a. Closing the emission price gap. Global Environmental Change $31,132-143$.

Edenhofer, O., Kalkuhl, M., 2011. When do increasing carbon taxes accelerate global warming? A note on the green paradox. Energy Policy 39(4), 2208-2212.

Edenhofer, O., Mattauch, L., Siegmeier, J., 2015b. Hypergeorgism: When rent taxation is socially optimal. FinanzArchiv / Public Finance Analysis 71(4), 474-505.

Fawcett, T., 2010. Personal carbon trading: A policy ahead of its time? Energy Policy 38(11), 6868-6876.

Feldstein, M. S., 1977. The surprising incidence of a tax on pure rent: A new answer to an old question. Journal of Political Economy 85(2), 349-360.

Fleming, D., 1997. Tradable Quotas: Setting Limits to Carbon Emissions. Lean Economy Papers, Lean Economy Initiative, Elm Farm Research Centre. 
Frey, B. S., 1999. Morality and rationality in environmental policy. Journal of Consumer Policy 22(4), $395-417$.

Fullerton, D., Metcalf, G. E., 2001. Environmental controls, scarcity rents, and pre-existing distortions. Journal of Public Economics 80, 249-267.

Goulder, L. H., 2013. Climate change policy's interactions with the tax system. Energy Economics 40, S3-S11.

Groth, C., Schou, P., 2007. Growth and non-renewable resources: The different roles of capital and resource taxes. Journal of Environmental Economics and Management 53(1), 80-98.

Heijdra, B. J., Kooiman, J. P., Ligthart, J. E., 2006. Environmental quality, the macroeconomy, and intergenerational distribution. Resource and Energy Economics 28(1), 74-104.

Hillman, M., 1998. Carbon budget watchers. Town and Country Planning 67, 305.

IEA, 2014. World Energy Investment Outlook. Special report of the International Energy Agency.

IPCC, 2013. Summary for Policymakers. In: Stocker, T., Qin, D., Plattner, G.-K., Tignor, M., Allen, S., Boschung, J., Nauels, A., Xia, Y., Bex, V., Midgley, P. (Eds.), Climate Change 2013: The Physical Science Basis. Contribution of Working Group I to the Fifth Assessment Report of the Intergovernmental Panel on Climate Change, Cambridge University Press, Cambridge, UK, and New York, USA.

IPCC, 2014. Summary for policymakers. In: Edenhofer, O., Pichs-Madruga, R., Sokona, Y., Farahani, E., Kadner, S., Seyboth, K., Adler, A., Baum, I., Brunner, S., Eickemeier, P., Kriemann, B., Savolainen, J., Schlömer, S., von Stechow, C., Zwickel, T., Minx, J. (Eds.), Climate Change 2014: Mitigation of Climate Change. Contribution of Working Group III to the Fifth Assessment Report of the Intergovernmental Panel on Climate Change, Cambridge University Press, Cambridge.

Kalkuhl, M., Brecha, R. J., 2013. The carbon rent economics of climate policy. Energy Economics 39, 89-99.

Karp, L., Rezai, A., 2014. The political economy of environmental policy with overlapping generations. International Economic Review 55(3), 711-733.

Karp, L., Rezai, A., 2015. Asset prices and climate policy. Mimeo.

Koch, N., Grosjean, G., Fuss, S., Edenhofer, O., 2016. Politics matters: Regulatory events as catalysts for price formation under cap-and-trade. Journal of Environmental Economics and Management 78, $121-139$.

Koethenbuerger, M., Poutvaara, P., 2009. Rent taxation and its intertemporal welfare effects in a small open economy. International Tax and Public Finance 16(5), 697-709.

Mankiw, N. G., 2008. Principles of Economics. Cengage Learning, 5th edition.

McKibbin, W. J., 2012. A new climate strategy beyond 2012: lessons from monetary history. The Singapore Economic Review 57(03), 1250016-1 - 1250016-18.

McKibbin, W. J., Wilcoxen, P. J., 2002. Climate change policy after Kyoto: Blueprint for a realistic approach. Brookings Institution Press.

McKibbin, W. J., Wilcoxen, P. J., 2007. A credible foundation for long-term international cooperation on climate change. In: Architectures for agreement: addressing global climate change in the post-Kyoto world, Cambridge University Press Cambridge.

Meinshausen, M., Meinshausen, N., Hare, W., Raper, S. C. B., Frieler, K., Knutti, R., Frame, D. J., Allen, M. R., 2009. Greenhouse-gas emission targets for limiting global warming to $2^{\circ} \mathrm{C}$. Nature $458(7242)$, $1158-1162$.

Mumy, G. E., 1980. Long-run efficiency and property rights sharing for pollution control. Public Choice $35(1), 59-74$. 
Petrucci, A., 2006. The incidence of a tax on pure rent in a small open economy. Journal of Public Economics 90(4-5), 921-933.

Pezzey, J. C., Jotzo, F., 2012. Tax-versus-trading and efficient revenue recycling as issues for greenhouse gas abatement. Journal of Environmental Economics and Management 64(2), 230-236.

Popp, D., Newell, R. G., Jaffe, A. B., 2010. Energy, the Environment, and Technological Change. In: Handbook of the Economics of Innovation, volume 2, pp. 873-937, Elsevier.

Rausch, S., 2013. Fiscal consolidation and climate policy: An overlapping generations perspective. Energy Economics 40, S134-S148.

Rubin, J. D., 1996. A model of intertemporal emission trading, banking, and borrowing. Journal of Environmental Economics and Management 31(3), 269-286.

Salant, S. W., 2016. What ails the European Union's emissions trading system? Journal of Environmental Economics and Management 80, 6-19.

Segal, P., 2011. Resource rents, redistribution, and halving global poverty: The resource dividend. World Development 39(4), 475-489.

Siegmeier, J., Mattauch, L., Franks, M., Klenert, D., Schultes, A., Edenhofer, O., 2017. The fiscal benefits of stringent climate change mitigation: an overview. Under review.

Sinclair, P. J. N., 1994. On the optimum trend of fossil fuel taxation. Oxford Economic Papers 46, 869-877.

Stiglitz, J. E., 2016a. How to restore equitable and sustainable economic growth in the united states. American Economic Review 106(5), 43-47.

Stiglitz, J. E., 2016b. New Theoretical Perspectives on the Distribution of Income and Wealth Among Individuals. In: Basu, K., Stiglitz, J. E. (Eds.), Inequality and Growth: Patterns and Policy, Volume I: Concepts and Analysis, IEA Conference Volume No. 156-I, Palgrave Macmillan, New York.

Turnovsky, S. J., 2000. Fiscal policy, elastic labor supply, and endogenous growth. Journal of Monetary Economics 45(1), 185-210.

World Bank, Ecofys, Vivid Economics, 2016. State and Trends of Carbon Pricing 2016 (October). Technical report, The World Bank, Washington, D.C.

Yaari, M. E., 1965. Uncertain lifetime, life insurance and the theory of the consumer. Review of Economic Studies 32(2), 137-150. 


\section{A Appendix [for online publication only]}

\section{A.1 Individual optimization}

3 This appendix provides the derivations for the individual dynamics described in Section

4 3.1: first, the Keynes-Ramsey rule and the arbitrage condition are derived from the first5 order conditions of the individual maximization problem. Second, and based on this, a

6 lifetime budget constraint is derived to finally obtain individual consumption.

7 The budget constraint (6] can be split into a constraint in monetary terms and another 8 in terms of the fossil resource by defining $d(\nu, t)=\phi s(\nu, t)-\dot{s}(\nu, t)-\bar{e}$, where $\bar{e}=\bar{E} / S s=$ $9 \quad \sigma s$. Dropping the time arguments, we obtain:

$$
\begin{aligned}
& \dot{k}=w+[r+\phi] k+(1-T) \sigma b s+p d-z-c \\
& \dot{s}=\phi s-d-\sigma s .
\end{aligned}
$$

10 Individuals maximise utility given by Equation (5) by choosing $c(\nu, t)$ and $d(\nu, t)$, subject 11 to Equations A1, (A2 and the transversality condition (9). Writing $\lambda$ and $\mu$ for the 12 multipliers of $(\mathrm{A} 1)$ and $(\mathrm{A} 2)$ in the current value Hamiltonian $H_{c}$, we obtain the following 13 first order conditions:

$$
\begin{aligned}
& \frac{\partial H_{c}}{\partial c}=\frac{1}{c}-\lambda=0 \\
& \frac{\partial H_{c}}{\partial d}=\lambda p-\mu=0 \\
& \frac{\partial H_{c}}{\partial k}=(\rho+\phi) \lambda-\dot{\lambda} \quad \Rightarrow \quad \lambda(r+\phi)=(\rho+\phi) \lambda-\dot{\lambda} \\
& \frac{\partial H_{c}}{\partial s}=(\rho+\phi) \mu-\dot{\mu} \quad \Rightarrow \quad \lambda(1-T) \sigma b+\mu(\phi-\sigma)=(\rho+\phi) \mu-\dot{\mu} .
\end{aligned}
$$

Inserting the time derivative of (A3) into Equation (A5) yields the Keynes-Ramsey rule (12). Using Equation A4 and its time derivative to replace $\mu$ and $\dot{\mu}$ in Equation A6 and applying Equation (A5) gives the arbitrage condition for investing in fossil resources or capital (13).

We can now derive an individual lifetime budget constraint from the instantaneous 
budget identity (6]), transversality condition (9) and no-arbitrage condition (13) :

Regrouping terms in (6]) and adding $\dot{p} s-(r+\phi) p s$ on both sides gives:

$$
\begin{aligned}
\dot{k}+p \dot{s}+\dot{p} s-(r+\phi)(k+p s) & =w+(1-T) \sigma b s-p \sigma s+\dot{p} s-r p s-z-c= \\
& =w-z-c .
\end{aligned}
$$

1 The last equality follows from (13). This leads to

$$
\begin{aligned}
\frac{d}{d \tau}\left[(k(\nu, \tau)+p(\tau) s(\nu, \tau)) e^{-R(t, \tau)}\right] & =(w(\tau)-z(\nu, \tau)-c(\nu, \tau)) e^{-R(t, \tau)} \\
\Rightarrow \int_{t}^{\infty} \frac{d}{d \tau}\left[(k(\nu, \tau)+p(\tau) s(\nu, \tau)) e^{-R(t, \tau)}\right] \mathrm{d} \tau & =\int_{t}^{\infty}(w(\tau)-z(\nu, \tau)-c(\nu, \tau)) e^{-R(t, \tau)} \mathrm{d} \tau \\
\Rightarrow \int_{t}^{\infty} c(\nu, \tau) e^{-R(t, \tau)} \mathrm{d} \tau & =k(\nu, t)+p(t) s(\nu, t)+h(\nu, t) \\
\text { with } h(\nu, t) & =\int_{t}^{\infty}[w(\tau)-z(\nu, \tau)] e^{-R(t, \tau)} \mathrm{d} \tau
\end{aligned}
$$

22 For the integration of the left-hand side in the last step, we used $\exp (-R(t, t))=1$ and Equation (9). Equation (A7) is the lifetime budget constraint, written here in the more general form with age-dependent transfers/taxes $z(\nu, \tau)$. It states that the present value of the consumption plan at time $t$ of individuals born at $\nu$ equals their total wealth of capital, fossil resources and the present values of lifetime labor income and (potentially age-dependent) taxes/transfers.

Finally, the individual consumption level follows from solving the Keynes-Ramsey rule for $c$, which gives

$$
c(\nu, \tau)=c(\nu, t) \exp \left(\int_{t}^{\tau}(r(\tau)-\rho) \mathrm{d} \tau\right)
$$

30 and substituting this into the lifetime budget (A7),

$$
\begin{aligned}
k(\nu, t)+p(t) s(\nu, t)+h(\nu, t) & =\int_{t}^{\infty} c(\nu, t) e^{\int_{t}^{\tau}[r(\tilde{t})-\rho] \mathrm{d} \tilde{t}} e^{-R(t, \tau)} \mathrm{d} \tau= \\
& =c(\nu, t) /(\rho+\phi) .
\end{aligned}
$$

Hence, individual consumption is a fixed fraction of wealth, and for age-independent transfers for which $h(\nu, t)$ simplifies to $h(t))$, Equation (14) holds. 


\section{A.2 Aggregate solution}

We derive the aggregate quantities for general age-dependent transfers $z(\nu, t)$, and then simplify them for uniform transfers to obtain the relations given in the main text.

The aggregate consumption level $C(t)$ for general transfers, as given by Equation (15) in the main text, is obtained directly from aggregation of Equation (14) and using (7). Note that for age-independent taxes/transfers, $H(t)=\int_{-\infty}^{t} h(t) \phi e^{\phi(\nu-t)} \mathrm{d} \nu=h(t)$.

The dynamics of the total capital stock (16) are obtained by applying Leibniz' rule to

$$
K(t)=\int_{-\infty}^{t} k(\nu, t) \phi e^{\phi(\nu-t)} \mathrm{d} \nu
$$

40 replacing $\dot{k}$ by its expression from the individual budget constraint (6]), and using Equation (7) for aggregate changes in resource ownership:

$$
\begin{aligned}
\dot{K}(t) & =\underbrace{k(t, t)}_{=0} \phi e^{\phi(t-t)}-0+\int_{-\infty}^{t} \frac{\mathrm{d}}{\mathrm{d} t}\left[k(\nu, t) \phi e^{\phi(\nu-t)}\right] \mathrm{d} \nu= \\
& =-\phi K(t)+\int_{-\infty}^{t} \dot{k}(\nu, t) \phi e^{\phi(\nu-t)} \mathrm{d} \nu= \\
& =w(t)+r(t) K(t)+[1-T(t)] \sigma b(t) S-p(t) \sigma S+ \\
& +p(t) \underbrace{\left[\phi S-\int_{-\infty}^{t} \dot{s}(\nu, t) \phi e^{\phi(\nu-t)} \mathrm{d} \nu\right]}_{=\bar{E}=\sigma S}-C(t)-\underbrace{\int_{-\infty}^{t} z(\nu, t) \phi e^{\phi(\nu-t)} \mathrm{d} \nu}_{=-T(t) b(t) \sigma S+I_{A}}= \\
& =w(t)+r(t) K(t)+\sigma b(t) S-I_{A}-C(t) .
\end{aligned}
$$

2 The government budget constraint (10) was used in the last step, showing that even in the more general case with age-dependent taxes/transfers $z(\nu, t)$, the aggregate result does not directly depend on the transfer scheme (however, it may have an indirect effect via prices, stock levels and consumption).

Similarly, we derive the dynamics of aggregate consumption, first for the case of general, 


$$
\begin{aligned}
\dot{C}(t) & =c(t, t) \phi e^{\phi(t-t)}-0+\int_{-\infty}^{t} \frac{\mathrm{d}}{\mathrm{d} t}\left[c(\nu, t) \phi e^{\phi(\nu-t)}\right] \mathrm{d} \nu= \\
& =\phi(\rho+\phi)[h(t, t)]-\phi C(t)+\underbrace{\int_{-\infty}^{t} \dot{c}(\nu, t) \phi e^{\phi(\nu-t)} \mathrm{d} \nu}_{=(r(t)-\rho) C(t)}= \\
& =[r(t)-\rho] C(t)-\phi(\rho+\phi)[K(t)+p(t) S-\bar{Z}(t)+\bar{z}(t, t)], \\
\text { with } \bar{Z}(t) & \equiv \int_{-\infty}^{t} \bar{z}(\nu, t) \phi e^{-\phi(t-\nu)} \mathrm{d} \nu \quad \text { and } \quad \bar{z}(t, t) \equiv \int_{t}^{\infty} z(t, \tau) e^{-R(t, \tau)} \mathrm{d} \tau .
\end{aligned}
$$

48 The first equality follows from Leibniz' rule. For the second, $c(t, t)=(\rho+\phi)[k(t, t)+$ $\left.{ }_{49} p(t) s(t, t)+h(t, t)\right]=(\rho+\phi)[h(t, t)]$ is used. In the third step, $\phi C(t)$ is replaced using

50 Equation (15). Alternatively, we could have directly differentiated Equation (15) and used ${ }_{51}$ that, by Leibniz' rule, $\dot{H}=(r+\phi) H-w+Z+\phi(\bar{Z}-\bar{z}(t, t))$. We thus obtain

$$
\frac{\dot{C}(t)}{C(t)}=r(t)-\rho-\phi(\rho+\phi) \frac{K(t)+p(t) S(t)-\bar{Z}(t)+\bar{z}(t, t)}{C(t)} .
$$

52 This is the general result on which the argument in Section 5 is based. For the special case 53 of uniform, age-independent transfers,

$$
z(\nu, t)=z_{u}(t)
$$

${ }_{54}$ we have $\bar{Z}(t)=\bar{z}(t, t)=\bar{z}_{u}(t)$ and Equation A8 simplifies to Equation (17) in the main text.

\section{${ }_{56}$ A.3 Properties of the aggregate dynamic system}

With extraction- and resource policies $(11)$ and (18), the dynamics of the aggregate economy are described by (13), (16) and (17). Balanced paths are described by (20,23). We denote by $\left(K^{L}, C^{L}, p_{0}^{L}\right)$ and $\left(K^{H}, C^{H}, p_{0}^{H}\right)$ the fixed points corresponding to the low- and high-value combinations of $K$ and $C$ that satisfy (21, 23), i.e. the lower and upper intersection of the parabola and the hyperbola in Figure 1 .

Linearizing around these points shows that $\left(K^{L}, C^{L}, p_{0}^{L}\right)$ is unstable. The point corre- 
sponding to the upper intersection $\left(K^{H}, C^{H}, p_{0}^{H}\right)$ is a saddle point with one stable arm. $C$ is a jump variable that instantaneously adjusts to satisfy the optimality and transversality conditions, so the system is on the stable path - see Edenhofer et al. (2015b) and appendices of Petrucci (2006). The only difference here is that we subtract a constant from one of the differential equations of the dynamical system examined in these previous papers. Our assumptions about $I_{A}^{*}$ (that it is sufficiently small for intersections to exist, and to be financed by carbon pricing) ensure that this does not change the topology of the phase space and thus also not its stability properties.

\section{A.4 Formal proof of the portfolio effect}

Proof of the theorem in Section 3.3. The idea of the proof is to compare the steady state of the decentralized equilibrium for two different auctioned shares of permits (or tax rates on resource extraction revenues): It will be shown that although for a fixed capital stock, consumption, and thus social welfare, is lower with a higher auctioned share, both the consumption and the capital stock are higher in the steady state, the higher the auctioned share is. This is illustrated in Figure 1 .

Consider two auctioning shares, $0 \leq T_{1}<T_{2} \leq 1$. Let the steady state defined by Equations (21) and (22) for the two shares be denoted by $\left(K^{1 *}, C^{1 *}\right)$ and $\left(K^{2 *}, C^{2 *}\right)$. The superscripts 1 and 2 also indicate the respective cases for the parabola and the hyperbola. From the definition of social welfare given in Section 3.3, it is sufficient to prove that

$$
C^{1 *}<C^{2 *}
$$

The parabola 21 (defined by $\dot{K}=0$ ) is not affected by the auctioned share. However the 4 hyperbola 22 (defined by $\dot{C}=0$ ) changes: It is equivalent to the following expression

$$
C_{H}^{i}(K)=\phi \frac{\rho+\phi}{r(K)-\rho}\left\{K+\frac{\sigma b_{0}(K) S_{0}}{r(K)}-T_{i} \frac{\sigma b_{0}(K) S_{0}}{r(K)}\right\}
$$

5 for $i=1,2$. As the last term in the curly bracket is negative, it follows that $C_{H}^{2}(K)<$ 
$C_{H}^{1}(K)$ for all $K \in\left[0, K^{k r}\right]$. In Figure 1 , the hyperbola for $T_{2}$ is below that for $T_{1}$.

For any $K<K^{1 *}$, we also have $C_{H}^{1}(K)<C_{P}^{1}(K)$ and $C_{P}^{1}(K)=C_{P}^{2}(K)$ since the parabola is independent of $T$. Hence $C_{H}^{2}(K)<C_{P}^{2}(K)$ for $K<K^{0 *}$. Moreover, $C_{H}^{i}(K)$ is positive for all $K \leq K^{k r}$, and thus tends to $+\infty$ as $K$ approaches $K^{k r}$. Thus the (nontrivial) intersection of parabola and hyperbola for $T_{2}$ must occur at a capital stock $K^{2 *}$ with $K^{1 *} \leq K^{2 *}<K^{k r}$. In this interval, $C_{P}(K)$ is increasing in $K$, thus $K^{1 *}<K^{2 *}$ and also $C^{1 *}<C^{2 *}$, as required.

\section{A.5 Applicability to carbon taxes}

This appendix shows that if climate policy is implemented by a carbon tax rather than by an emission permit scheme, it still induces a shift in investment away from fossil resource stocks and towards (previously underaccumulated) capital, so that a beneficial portfolio effect occurs. However, since resource extraction is endogenous under a tax, a continuous OLG model with a carbon tax is only amenable to our analytic approach for tax paths that lead to balanced paths of the economy (which can then be compared to each other and to the socially optimal balanced path). This is a strong restriction, because as we will show below, it implies that we can only fully analyze tax paths that do not affect the timing of resource extraction. In other words, we are restricted to the analysis of cases in which the carbon tax collects rents, but has no climate change mitigation effect by extraction postponement.

Of course, all practically implemented carbon taxes also reduce resource extraction and GHG emissions via a volume effect, because they apply in proportion to some physical unit of the fossil resource (World Bank et al., 2016) and this fixed markup reduces demand and thus leads to resource conservation (Edenhofer and Kalkuhl, 2011). As explained in Section 3.4 of the main text, we thus expect that a carbon tax can implement any combination of mitigation- and rent collection targets, just like an emission permit scheme. However, formally proving this would require a more detailed model of the resource sector, and solving its full initial value problem. We refrain from this since the generality of our analysis of carbon taxes is already compromised by the restriction on tax paths, and our focus is on rent collection rather than resource extraction dynamics. Instead, we keep to a 
somewhat simpler model of a carbon tax, namely an ad valorem tax which cannot induce a volume effect, but suffices to formally show the occurrence of the macroeconomic portfolio effect due to rent collection on a balanced path.

We start our formal analysis by modifying the resource extraction part of our continuous OLG model for an ad valorem carbon tax. We then show that a balanced path requires a constant tax rate. The dynamical system in this case resembles the one with permits, so the theorem in Section 3.3 can be extended: a higher constant carbon tax level leads to higher social welfare. However, a constant tax does not affect the resource extraction path, so the only contribution to emission reductions is that the portfolio effect leads to a higher capital stock, which implies lower interest rates and thus slower extraction. Finally, we briefly consider the case of a falling ad valorem carbon tax rate: this offers at least some future rents to resource owners, which postpones extraction and induces climate change mitigation, but also implies that the beneficial portfolio effect cannot be maximized at the same time.

Assume an OLG model with two assets, capital and an exhaustible resource, as in Section 2 , but endogenous extraction under a (potentially time-dependent) carbon tax instead of an exogenously given extraction path implemented by a permit scheme. The carbon tax is interpreted as a tax on the value of extracted resources. Again, these carbon pricing revenues are used to finance resource efficiency improvements.

The firms' problem remains unchanged. On the demand side, with individual resource extraction $e$ as an independent control variable, the individual budget identity (6) does not simplify to (61), and the path of the aggregate resource stock is endogenous according to (8). Individual optimization yields a simpler no-arbitrage condition than before, identical to the well-known Hotelling rule, and an additional condition on resource prices (we suppress time dependencies in the following):

$$
\begin{aligned}
\dot{p} / p & =r, \\
p & =(1-T) b .
\end{aligned}
$$$$
\left(13{ }^{\prime} a\right)
$$

140 Thus, while resource extraction $e$ and resource stock ownership $s$ can be chosen separately, 
their prices are not independent. However, they may grow at different rates: Combining the two conditions gives

$$
\dot{b} / b=r+\psi \quad \text { with } \quad \psi:=\dot{T} /(1-T),
$$

so a decreasing tax rate $(\psi<0)$ implies that $p$ grows faster than $b$. From the firms' first-order conditions (2), we have

$$
\frac{\dot{b}}{b}=\frac{\dot{F}_{E}(K, L, A, E)}{F_{E}(K, L, A, E)}=\frac{\dot{A}}{A}+\frac{\dot{K} F_{E K}}{F_{E}}+\frac{(\dot{A} E+A \dot{E}) F_{E E}}{A F_{E}}
$$

Substituting this into $\left(\left.13\right|^{\prime \prime} c\right)$ and solving for $\dot{E}$ shows that ceteris paribus (in particular for constant $K$ ), the resource extraction rate depends on the rate of change of the tax rate, but not on the rate itself.

The dynamics of aggregate capital and consumption remain almost unchanged:

$$
\begin{aligned}
& \dot{K}=w+r K+b E-I_{A}-C, \\
& \frac{\dot{C}}{C}=r-\rho-\phi(\rho+\phi) \frac{K+p S}{C} .
\end{aligned}
$$

Compared to the case with permits, only the government-controlled extraction $\bar{E}(t)$ has been replaced by $E(t)$, which is determined endogenously from the households' problem above.

The government takes into account the firms' and households' first-order conditions (thus being the leader in a Stackelberg game) when it chooses the tax rate $T$ and public investment $I_{A}$ in resource efficiency improvements governed by $(3)$. These are balanced in the government's budget (10) by lump-sum taxes or transfers $Z$, if necessary.

Assume that the government seeks to establish a balanced path with $K(t)=K^{*}, C(t)=$ $C^{*}$. It follows from Equation $11^{\prime}$ ) that this requires the marginal resource productivity to grow as fast as resource supply declines (otherwise output is not constant), while for the generation-replacement effect in Equation (17) to stay constant, the resource stock price 
has to grow as fast as the resource stock declines, so we have

$$
\begin{gathered}
\frac{d}{d t}(A E)=0, \\
\frac{d}{d t}(p S)=0 .
\end{gathered}
$$

161

$$
\begin{aligned}
\dot{S} / S & =-E / S, \\
\dot{b} / b & =\psi-\dot{S} / S \quad(\text { for }(1-T) b S \neq 0), \\
\dot{b} / b & =\psi+r .
\end{aligned}
$$

\footnotetext{
${ }^{23}$ It can be shown that for a unit carbon tax, a balanced path requires $\dot{T} / T=r$.
} 


$$
\dot{b} / b=\dot{p} / p=\dot{A} / A=-\dot{E} / E=-\dot{S} / S=r\left(K^{*}\right),
$$

since as long as the carbon tax and R\&D investment are constant, the resource stock and resource extraction change at the same rate, so the price for the extracted resource and the stock also evolve at the same rate. A non-constant carbon tax would drive a wedge between them $(\dot{p} / p=r=\dot{b} / b-\psi)$.

A balanced path is consistent with a constant carbon tax of any rate (except $T=1$, for which the market for resource stocks would collapse and the market for the extracted resource would be purely demand-driven). On such a path, the contribution of resource wealth to the generation replacement effect is constant, but smaller for a higher carbon $\operatorname{tax}\left(p S=(1-T) b_{0}\left(K^{*}\right) S_{0}\right)$. Thus, the following result holds (proved at the end of this appendix):

Corollary. Assume that production can be described by a Cobb-Douglas function. Suppose the decreasing availability of fossil resources is exactly offset by technological progress, which is publicly financed by the revenues of a constant ad valorem carbon tax and, if necessary, lump-sum taxes. Then, the higher the constant carbon tax rate, the higher is social welfare.

As noted above, a constant tax does not directly affect the path of resource extraction and GHG emissions (Dasgupta and Heal, 1979). Nevertheless, it indirectly induces some climate change mitigation, because the portfolio effect leads to a higher capital stock and lower interest rate, so extraction is slower.

Finally, consider a non-constant ad valorem carbon tax that affects the endogenous extraction path (Dasgupta and Heal, 1979). The tax will need to decrease to provide an incentive for resource conservation and thus mitigation (Sinclair, 1994). As we saw above, this does not result in a balanced path in a continuous OLG setting since it implies different growth rates of the resource stock and the resource stock price, so that the generation replacement effect is non-constant. Hence, we cannot apply the same analytical method as above. Nevertheless, some part of the fossil resource rent still is extracted by the carbon tax, the value of the fossil stock is reduced and saving in producible capital becomes more 
attractive, so the basic effect can be expected to hold for such a non-constant carbon tax as well:

Conjecture. The macroeconomic portfolio effect still holds under a time-dependent ad valorem carbon tax.

Compared to a permit scheme or a unit carbon tax, even a time-varying ad valorem carbon tax is less flexible: since it can only induce mitigation by extraction postponement, some future rents need to be privately retained, so there is an upper limit on the degree of rent collection that is consistent with a given level of climate change mitigation, and a tradeoff between further rent collection and mitigation beyond that. This contrasts with a permit scheme, in which the amounts available for extraction can be chosen independently from the auctioning rates (which may be constant, as above, or vary over time). It also contrasts with a unit carbon tax, which may employ a volume effect that keeps some fossil resources in the ground forever if the initial tax is high enough (Edenhofer and Kalkuhl, 2011) and still collect all rents, as discussed in Section 3.4. Thus, if climate policy is implemented by a decreasing ad valorem carbon tax, the beneficial macroeconomic portfolio effect cannot be exploited to the same extent that is possible under a permit scheme with a constantly high auctioning rate, or under a unit tax.

If other (for example political) factors imply a limit on feasible rent collection below the level consistent with mitigation by a decreasing tax, this equalizes the maximally feasible portfolio effect under an ad valorem tax, a unit tax or a permit scheme. Both types of carbon taxation and permit schemes may then replicate each other, as pointed out by Fullerton and Metcalf (2001).

Proof of Corollary A.5. We first describe the aggregate dynamical system for the case of a constant ad valorem carbon tax. We then show that the theorem in Section 3.3 of the main text extends to this case. 


$$
\begin{aligned}
\dot{S} & =-E \\
\dot{p} / p & =r \quad \text { and } \quad p=(1-T) b, \\
\dot{b} / b & =r+\psi \quad \text { with } \quad \psi:=\dot{T} /(1-T), \\
\dot{K} & =F(K, L, A E)-\delta K-I_{A}-C, \\
\dot{C} / C & =r-\rho-\phi(\rho+\phi)(K+p S) / C, \\
\dot{A} & =\theta I_{A} A
\end{aligned}
$$

The essential dynamical system can now be written as

$$
\begin{aligned}
\dot{S} / S & =-E / S \\
\dot{E} / E & =\alpha \dot{K} / K-r(K), \\
\dot{K} / K & =[F(K)-\delta K-C+\dot{E} /(\theta E)] / K, \\
\dot{C} / C & =r(K)-\rho-\phi(\rho+\phi)[K+(1-T) \beta F(K) S / E] / C .
\end{aligned}
$$


Substituting (A16) into A17 and defining $\epsilon:=E / S$, we obtain

$$
\begin{aligned}
\dot{S} / S & =-\epsilon, \\
\dot{\epsilon} / \epsilon & =\epsilon+\alpha \dot{K} / K-r(K), \\
\dot{K} / K & =[F(K)-\delta K-C-r(K) / \theta] \theta /(\theta K-\alpha), \\
\dot{C} / C & =r(K)-\rho-\phi(\rho+\phi)[K+(1-T) \beta F(K) / \epsilon] / C .
\end{aligned}
$$

$$
\begin{aligned}
\epsilon & =r(K), \\
C & =F(K)-\delta K-r(K) / \theta, \\
C & =\phi(\rho+\phi)[K+(1-T) \beta F(K) / r(K)] /[r(K)-\rho] .
\end{aligned}
$$

${ }_{237}$ In the $C$ - $K$-plane, the last two equations describe a parabola and hyperbola as before (cf. Equations (21) and (22)). The fixed point is stable, since the same argument as in Appendix A.3 applies (in this case with two jump variables, $C_{0}$ and $\epsilon_{0}=E_{0} / S_{0}$ chosen such that the transversality conditions are met).

Thus, the occurrence of a macroeconomic portfolio effect under an ad valorem carbon 242 243

$$
C_{H}^{i}(K)=\phi \frac{\rho+\phi}{r(K)-\rho}\left\{K+\frac{\beta F(K)}{r(K)}-T_{i} \frac{\beta F(K)}{r(K)}\right\}
$$

